\title{
Student Teachers' Perceptions of Poverty and Educational Achievement.
}

\section{Ian Thompson, Jane McNicholl and Ian Menter. University of Oxford}

\section{Abstract}

This paper reports on a mixed methods study carried out within the Initial Teacher Education (ITE) programme at the University of Oxford on the ways that the course sought to frame and address the link between poverty and poorer educational outcomes. The study was concerned with the views held by ITE students on the effects of poverty on pupils' learning, well-being, and educational achievement. The paper initially explores why these questions are important, how they are framed internationally, and how they relate to current education policy, particularly in England.

Data were collected from student teacher pre- and post PGCE course questionnaires and a focus group discussion. The findings showed a tendency for student teachers to associate low achievement more strongly with family and cultural factors than with socio-economic or school factors, although there was some evidence that the thinking of some students changed during their programme. Implications for policy and practice in ITE are discussed with a view to ensuring that the social justice commitments espoused by many such courses are actually enabled more effectively to influence the learning experiences of beginning teachers.

Keywords: poverty, educational achievement, student teacher perceptions, social justice

\section{Introduction}

This paper draws on research from a programme of work on Poverty and Teacher Education (PATE) being carried out by colleagues at several education departments across England. Here we offer a particular focus on our own local context of Oxfordshire and our own teacher education programme at the University of Oxford.

The research reported here adopted a mixed methods approach aimed at developing our understanding of the ways programmes of Initial Teacher Education (ITE) - taking our own programme as a case - can seek to address the impact that poverty can have on young people's life chances. We critically examine some of the key terms used in the literature related to poverty, ITE and pupils' educational outcomes. The article reports on an empirical study of student teachers' developing understandings of and attitudes towards poverty and 
their own role in relation to challenging inequality. An examination of the stated aims and practice of the University of Oxford ITE programme reveals the ways that university tutors seek to address issues of poverty and inequality among learners with their student teachers.

It is an expectation of all teacher education programmes in England that they will support beginning teachers to meet the needs of all learners, including those who are most disadvantaged (DfE 2013). This article aims to prompt a discussion about the future of ITE programmes in ensuring that the new generation of teachers are fully prepared to meet the needs of all pupils, including those living in poverty. It is not suggested that teacher education alone can eliminate these deeply rooted issues, but that there is a significant role to be played by all of those involved - both in the initial preparation of teachers but also in continuing professional development. We suggest that programmes of ITE need to address key issues related to teaching pupils from disadvantaged and impoverished backgrounds. This initial study sought to explore student teachers' developing understandings of the influences of economic disadvantage on educational achievement and subsequent life opportunities. The two key research questions were:

1. How do programmes of ITE frame and seek to address the link between poverty and poorer educational outcomes?

2. To what extent do student teachers' understandings of and attitudes towards poverty change or develop during their programme of study?

\section{Background - the English context}

Poverty is remarkably persistent in the wealthiest societies. The work of Wilkinson and Pickett (2009) shows how inequality is damaging to societies and that the UK is among the most unequal societies in the 'developed world'. The geographer Danny Dorling (2011) has further demonstrated how localised the spatial patterns of poverty and wealth may be and how closely they are associated with educational achievement. Much education policy discourse adopted by governments across Europe over recent years has sought to address these matters, but educational inequalities persist (e.g. Ball 2006; Raffo et al. 2007). Indeed, the market based policies introduced by successive governments in Europe and the US have led to greater social and economic polarisation in schooling, especially in large cities. Austerity measures are likely to have exacerbated this inequality. Research has consistently 
shown that the most economically disadvantaged pupils have the poorest educational outcomes (e.g. Hills et al. 2010; Lupton, 2006; Marshall, 2002) and that the institution of schooling has consistently failed young people from disadvantaged socio-economic backgrounds (e.g. Ball, 2003; Horgan 2007).

In the USA there has been some exploration of these matters and scholars such as Zeichner (2009), Ladson-Billings (2006), Nieto (2000) and Cochran-Smith (2004) have all in various ways engaged with closely related themes - although disadvantage in this work has often been associated with 'race'. While a number of authors have consistently considered the role that ITE might have in overcoming inequalities (e.g. Cochran-Smith, 2004; Zeichner 2009), remarkably little research exists that directly addresses any linkages between poverty and teacher education. More recently, Gorski and others have drawn attention to the impact that socio-economic disadvantage can have on young people's life chances (Buras 2014; Gorski 2012; Gorski \& Landsman 2013). Much of this work has sought to critique the 'culture of poverty' that has come to dominate much of the discourse from politicians, media commentators and in some cases educationalists (Payne 2005). Here the 'culture of poverty' refers to the term that neoconservatives utilise to explain why pupils living in poverty have poorer educational outcomes; the argument being such children lack the necessary dispositions and cultural assets to do well in school (Buras 2014). Gorski (2012) argues that this 'culture of poverty' is underpinned by a deficit ideology or deficit thinking, where the shortcomings of the poor, rather than structural inequalities, are used to explain why children who live in economic disadvantage more often than not have poor educational outcomes (also see: Dudley-Marling \& Lucas 2009; Gorski 2011; Sleeter 2004; Valencia 1997). Research suggests that such an ideology, is an issue of ignorance about the lives of 'others' where the human tendency is 'to imagine our own social and cultural identity groups as diverse while we imagine "the other", people belonging to a social or cultural identity group with which we are less familiar, as being, for all intents and purposes, monolithic' (Gorski 2012, pp. 302-303; also see Clark 1985; Hurst 2007).

Gorski (2012) warns of the dangers of this ignorance when he asserts that in comparison to understandings about the impact ethnic background has on educational achievement, more ignorance abounds about the impact of socio-economic class. When in unfamiliar contexts, the default of cognitive reasoning is to rely upon intuition and stereotyped beliefs about 
certain groups or communities - in other words, we 'use stereotypes to fill in the blanks' (Gorski 2012, p. 303). In the US at least, it seems many people, including teachers and students teachers, not only believe people are poor because of their own deficiencies (Rank, Yoon \& Hirschl 2003) but also hold other stereotypical views about pupils and their families. As a result they believe that poor parents do not value education and pupils do not achieve because they are lazy (Patterson, Hale \& Stessman 2007). This 'deficit ideology', or indeed this 'culture of poverty', leads educators to define 'the problem in terms of students' inabilities to achieve and their families' inability to help them achieve rather than the many barriers that impede their achievement' (Gorski 2012, pp. 313-314). The pervasiveness of such deficit thinking and stereotyping, even among those teachers and student teachers apparently committed to educational equality, can lead to low expectations of poor students (Love 2004).

Seemingly, social justice agendas underpin many ITE programmes around the world (Freeman 2007; Zeichner 2009), including those in the UK; the aim being to prepare teachers who are capable of teaching all pupils, not just those who have been traditionally well served by schools. Ensuring beginning teachers possess the relevant knowledge, skills and dispositions to teach all learners equitably is a real imperative for PGCE courses in England (one year teacher preparation programmes undertaken by graduates). However, the broad knowledge and skills that all beginning teachers need to develop - a secure grasp of subject matter, an ability to transform this for learners, and the sensitivity to do so in a culturally responsive manner - are not sufficient tools to prepare them to overcome barriers to learning and to meet the needs of all learners, including poor children (Cochran-Smith \& Zeichner 2010; Darling-Hammond \& Bransford 2007; Villegas \& Lucas 2002). '[T]teachers who aim to make a difference in the lives of diverse students need the disposition to teach all learners equitably' (Villegas 2007, p. 372). Villegas defines 'dispositions' as 'tendencies for individuals to act in a particular manner under particular circumstances, based on their beliefs' (ibid, p. 373). Moreover, reviews of the teacher education literature provide strong evidence that student teachers' pre-existing beliefs shape their ITE experience (Pajares 1992; Richardson 1996; Wideen, Mayer-Smith \& Moon 1998). If stereotypical beliefs frame dispositions, any ITE programme claiming a social justice agenda cannot ignore the understandings of and attitudes towards people living in poverty held by their students. 
Given that "people are more likely to notice and remember information that confirms an applicable stereotype than information that disconfirms it' (Gorman 2005, p. 704) and student teachers' beliefs have been shown to be remarkably resistant to change, developing dispositions aligned to a more social justice agenda will be no easy task for teacher educators. Looking for insights from previous research is likely to be unfruitful, because, at least in the UK, little research has actually focused on the capacity of teacher preparation programmes to address educational inequities caused by poverty. The small amount of research that does exist suggests that teachers, including student teachers, do indeed hold stereotypical ideas about pupils and parents and consequently locate the causes of educational underachievement due to poverty within the pupil or the home rather than within institutional structures and practices (e.g. Gazeley and Dunne, 2005; Payne, 2005; Lupton and Thrupp, 2013; Thrupp, Mansell, Hawksworth and Harold, 2003).

In the UK (and we are focussing mainly on England here), we have had a number of aspirational statements about ensuring that good quality teacher preparation will lead to narrowing 'the achievement gap'. The Teach First programme (building on Teach for America) has explicitly sought to attract the 'best' graduates into the most challenging school circumstance. But on both sides of the Atlantic there has been a notable absence of sustained research or evaluation in this area. Teach First has recently celebrated ten years of working in schools in the most disadvantaged urban areas. From the outset the programme has had a commitment to challenging disadvantage and this has been based on the proposition that the brightest and best graduates from elite universities are well-placed to assist in this. As the Teach First website puts it:

Our vision is that no child's educational success is limited by their socio-economic background. We train and support people with leadership potential to become inspirational teachers in schools in low income communities across the UK. These teachers change lives. They help young people believe in themselves, and empower them to build a future they may not have believed possible.

(www.TeachFirst.org.uk/AboutUs/; 12.08.13)

This is the ideology of education as a route to economic success. We may note that the function of Teach First is not to address the question of low income itself but to enable young people to escape from the future prospect of low incomes through education. This of course 
is very similar to the old discourse of selective education. The key difference however is that grammar school education was a route out of low income for a few, whereas the implication of Teach First is that education can be a route for everyone. There is a logical fallacy here that is rarely commented upon and yet it is a fallacy that also runs through most of the current government's social discourse in education. The fallacy can be demonstrated as follows:

There are low income and high income families;

Children from low income families are disadvantaged at school;

Better teaching can enable all children from low income families to overcome their disadvantage;

These children will earn high incomes as adults;

Not only will there therefore be no educational disadvantage, there will be no low income families.

So, who will undertake the low income occupations - those not requiring high levels of skill or knowledge - if everyone is highly paid and 'well educated'?

The same kind of flawed logic was certainly also there in many pronouncements made by Michael Gove, the former and influential Secretary of State for Education in England. For example in his foreword to the 2010 White Paper, The Importance of Teaching, Gove wrote:

Our schools should be engines of social mobility, helping children to overcome the accidents of birth and background to achieve much more than they may ever have imagined. But, at the moment, our schools system does not close gaps, it widens them.

Children from poorer homes start behind their wealthier contemporaries when they arrive at school and during their educational journey they fall further and further back. The achievement gap between rich and poor widens at the beginning of primary school, gets worse by GCSE and is a yawning gulf by the time (far too few) sit A levels and apply to university. 
This injustice has inspired a grim fatalism in some, who believe that deprivation must be destiny. But for this Government the scale of this tragedy demands action. Urgent, focused, radical action.

(DfE 2010, 6-7).

Surely the obvious conclusion to draw from this analysis is to close the income gap between rich and poor. It was Gove's own grim fatalism that ignored this possibility and placed the entire responsibility on the school system. Apparently what he was espousing was that that all children should have the opportunity to study in the environment of a well-funded private school, such as he himself and most of his colleagues in the Cabinet attended.

It seems curious therefore that the revised standards for teachers, that were implemented from September 2012 make no direct reference to this 'achievement gap'. Among the eight standards are:

1 Set high expectations which inspire, motivate and challenge pupils;

2 Promote good progress and outcomes by pupils;

and

5 Adapt teaching to respond to the strengths and needs of all pupils. (DfE 2013)

In defence of these statements it might perhaps be pointed out that not all teachers will be facing the challenges of raising attainment for pupils living in poverty, whereas the Standards must be applicable for all. Indeed Gove's central rhetoric may in some sense be seen as a systematic attempt to obfuscate the realities of economic and social inequality by suggesting that in some way educational inequalities are separate from them. But as Bernstein (1970) argued so many years ago, education cannot compensate for society!

\section{The Contexts of Poverty and Education in Oxfordshire}

Oxfordshire is a county of extremes of conspicuous wealth and localised poverty. Whilst the term 'Chipping Norton Set' has become a catchphrase for the perceived decadence of the Oxfordshire rich, child poverty has been identified as both a hidden and growing problem in the region. $11.7 \%$ of children in the county officially live in poverty, around half the national average. Yet this figure rises to $23.2 \%$ in the City of Oxford and to $36 \%$ in the Blackbird 
Leys area of Oxford. Oxfordshire is the most rural county in the South East of England and almost a quarter of all county children living in poverty reside in rural areas, thereby tending to be cut off from access to the appropriate support systems.

Education in the City of Oxford is very evidently both a class and a classroom issue. For a small city, Oxford has a large number of independent schools. In the state school sector, educational outcomes can broadly be associated with postal code. In Higher Education, the University of Oxford (one of two universities in the city) is a consciously elite institution with a worldwide reputation for excellence in research and teaching. The University acts as a major employer in the city and it is one of the sources of the relative economic wealth of the region. Only $11.5 \%$ of Oxford undergraduates describe themselves as working class (Guardian, 2010) and you are 55 times less likely to go to Oxford or Cambridge if you are receiving free school meals than if you are not. In this context it comes as a surprise to many that the pre-service, or ITE, Postgraduate Certificate of Education (PGCE) programme of the University of Oxford's Department of Education (OUDE) works almost exclusively with local state secondary 'comprehensive' schools.

In the UK, PGCE programmes are typically provided by universities in partnership with schools; in fact, the Oxford Internship Scheme's PGCE was an early innovative model of ITE that was developed in close partnership with Oxfordshire secondary schools (e.g. Benton,1990; McIntyre, 1997; Hagger \& McIntyre, 2000). For over twenty five years, this close relationship has facilitated evidence-based empirical research in teacher education, subject-specific pedagogical knowledge, and beginning teachers as learners. Although there has been considerable diversification in the provision of ITE in England in recent times, with more school-led provision coming on stream, the one year PGCE course remains amajor route into secondary school teaching. The Government stipulates that during a PGCE course student teachers spend the majority of time in school ( 24 of the 36 week course) with the remainder of the time in the university. For the Oxford Internship Scheme, the 24 weeks are spread over two school placements, known as S1 and S2.

The Oxford PGCE programme is based on a commitment to pupils from all backgrounds having the right to high quality teaching and resources in an accessible comprehensive school. Yet teacher educators and prospective teachers dedicated to comprehensive schooling 8 
need to confront some uncomfortable questions that affect pupils living in poverty. Why are pupils in lower attaining groups in state schools overwhelmingly from impoverished backgrounds? Will the market-orientated discourse and practice that dominates the education system in the UK lead to further inequality between the wealthy and the poor? Do we, as teacher educators, challenge beginning teachers' perceptions of the causes for poor educational outcomes for children? The research reported here arose from a concern raised by university PGCE tutors about our student teachers' understanding of the link between poverty and educational achievement. Although our student teachers have all obtained good subject specific first degrees, they come from a more diverse social and economic background than their undergraduate counterparts. They bring to their learning a huge range of social and cultural experiences that mediate their experiences of poverty and pupil attainment in their two typically contrasting placement schools.

\section{Student Teachers' Perceptions of Poverty}

As we have seen, existing research on teachers' perceptions and attitudes to poverty in the classroom suggests that educators often lack a critical perspective on context and rely on deficit models from a middle class perspective of the norm). Research in the US (Cox, Watts and Horton, 2012) has indicated that student teachers' attitudes to poverty is often deeply ingrained. In the UK, however, as noted above, very little research addresses the issue of student teachers' perceptions of poverty or the role of teacher educators in addressing issues of poverty in the classroom.

As teacher educators, we are aware that our student teachers come from a range of backgrounds and hold a wide variety of views on the effects of poverty on educational attainment. Many of our students will have limited direct experience of poverty, yet all will encounter and teach pupils from disadvantaged backgrounds. Given these contexts, in the research reported here, we wanted to explore the question of how student teachers understand and empathise with the social, cultural, and emotional contexts of children living in poverty. The aim of the study was to investigate student teachers' understandings of and attitudes towards poverty, and their own role in relation to challenging inequality within schools.

\section{Methods}


The research arose from the perception of some university PGCE tutors that many of their student teachers had little understanding of the link between child poverty and educational attainment; indeed it seemed likely that such ignorance could lead to them defaulting to stereotyping poor students, their families and their communities (Gorski 2012). Since teachers' beliefs strongly frame dispositions with very real implications for classroom practice, we recognised as a team of teacher educators the need to address this issue on the course. With this in mind, we set out to explore the development of our student teachers' perceptions of the impact of poverty on children's educational outcomes. During the academic year 2012-13 we undertook a small scale study using a mixed methods approach involving the collection and analysis of both qualitative and quantitative data (Teddlie \& Tashakkori 2009). Specifically, surveys and interviews were used as different but complementary lenses to investigate student teachers' perceptions and, ultimately, generate better understandings of this (Somekh \& Lewin 2011). Qualitative data were collected from two whole course survey questionnaires at each end of the ITE programme with the OUDE PGCE cohort. Comments from the surveys were coded and the results used to provide a statistical summary. At the end of the course, but before the second survey, we also conducted a semi-structured focus group interview.

The two questionnaires - one at the beginning and one at the end of the course - were used to investigate student teachers' perceptions and their development over the course of the ITE programme. The first survey was delivered to 185 students from our seven subject areas and had an $85 \%$ response. The second was delivered to the 179 students remaining on the course with a 93\% reply rate. Two of the authors delivered a Professional Development Programme (PDP) session immediately after the first survey. In the second stage, the second survey and focus group interview, the aim was both to gauge student teachers' perceptions of poverty and also to determine what influence various aspects of the course had had on their beliefs: placement schools; school mentors; university tutors; university sessions.

\section{Findings: Phase One}

The pre-course survey ( $85 \%$ response rate) asked the student teachers to respond to a question about their own background income levels: $75 \%$ described themselves as middle income; $7 \%$ high; $15 \%$ low; and 3\% no income. Although it is not possible to discern from this response how the student teachers define their income levels relative to the rest of the 
population, it is reasonable to conclude that $82 \%$ of the cohort came from backgrounds where poverty was not an issue. The survey asked the student teachers to consider the effect on pupils' educational achievement of the following variables: social class, ethnicity, gender, parental/carer attitudes to education; parental/carer income (see Fig. 1).

\section{Fig 1 here}

They were then asked to rank these variables in order of significance. Table 1 shows which factors were ranked highest by the respondents:

What has the largest negative impact on pupils' educational outcomes, life choices and opportunities? $(n=157)$

\begin{tabular}{|l|l|}
\hline Parents'/Carers' Attitudes to Education & $81 \%$ \\
\hline Social Class & $8 \%$ \\
\hline Income Levels & $7 \%$ \\
\hline Gender & $3 \%$ \\
\hline Ethnicity & $1 \%$ \\
\hline
\end{tabular}

Table 1

Of course there are considerable limitations of such a survey question in assessing student teachers' attitudes to pupil poverty. However, the implication is that the majority of the student teachers believed that pupils who do less well at school do so because of their parents' or carers' low aspirations or negative attitudes to education rather than material and emotional factors relating to relative poverty. This may be seen as a cultural deficit view of the correlation between poverty and educational attainment. Yet recent research suggest that parents from working class and lower income backgrounds do, in fact, have high educational aspirations for their children (e.g. Cummings et al., 2012).

The results of this survey were presented to all the PGCE curriculum tutors at OUDE who were asked to consider raising these issues with the school mentors and in their own curriculum sessions. The PDP session that followed this survey sought to highlight and 
confront stereotypical assumptions of pupil aspirations and achievement (e.g. Gorski, 2012) through a theoretical and analytical lens.

The cohort was urged at the end of the session to go and explore issues of pupil poverty and social justice within the contexts of their placement schools. Throughout the year, curriculum tutors in subject areas referred to these issues in subject specific university sessions and the issue of poverty within local contexts was also addressed in PDP sessions held in schools.

\section{Findings: Phase Two}

The second survey, conducted at the very end of the course, began by asking the student teachers whether they agreed with the following assertion (Table 2).

\section{There is a link between poverty and pupils' educational outcomes, life choices \& opportunities: (n-166)}

\begin{tabular}{|l|l|l|}
\hline & Number & $\%$ \\
\hline Strongly agree & 71 & $43 \%$ \\
\hline Agree & 54 & $33 \%$ \\
\hline Disagree & 29 & $17 \%$ \\
\hline Strongly Disagree & 12 & $7 \%$ \\
\hline
\end{tabular}

Table 2

In many ways, the fact that $24 \%$ did not agree at the end of their PGCE course that there is a link between poverty and educational achievement is quite alarming for a course that made this link explicit through the sharing of research findings in University and school-based sessions. However, it could also be argued that the majority of the $76 \%$ of students who did understand the link between poverty and educational attainment fell back on deficit models for their interpretation of why this should be the case. 118 comments on the reasons for the given answers were coded for 4 different factors (Table 3): parental deficit; pupil deficit; school factors (positive and negative); and socio-economic factors. 18 comments were uncoded as they gave no reason or just restated the question. 


\begin{tabular}{|l|l|l|l|l|}
\hline & $\begin{array}{l}\text { Located within } \\
\text { parental deficit }\end{array}$ & $\begin{array}{l}\text { Located } \\
\text { within pupil } \\
\text { deficit }\end{array}$ & $\begin{array}{l}\text { Located within } \\
\text { school: positive } \\
\text { and negative }\end{array}$ & $\begin{array}{l}\text { Consequence } \\
\text { of socio- } \\
\text { economics }\end{array}$ \\
\hline Number & 48 & 23 & 9 & 38 \\
\hline$\%$ & 41 & 19.5 & 7.5 & 32 \\
\hline
\end{tabular}

Table 3

Examples of statements suggesting that low expectations or aspirations held by parents was the main cause included:

- "I think that students who come from less well off backgrounds are often (but not always) there because their parents have lower aspirations, therefore they are less likely to value their education leading to less opportunities in life."

- "Less push from parents, poorer attitude to education."

- "Pupils are highly affected by their family as a role model in terms of aspiration and attitudes to school."

Those who attributed the main cause to the pupils themselves included the following statements:

- "Lower aspirations - students don't feel that they can achieve as well as the other students"

- "Everyone has an equal chance to work hard during school and out of school. The more you put in yourself the more you get out."

The small number of responses which highlighted school responsibilities included:

- "Pupils can be stereotyped early on in their educational career. This leads to pupils and teachers to lower their expectations (or not see high expectations)."

- "There is currently a strong link between a pupil's socioeconomic background and their academic achievement. I do not believe that it cannot be overcome but in order to improve social mobility state schools need to be dramatically reformed and to have a culture of high expectations and of pushing high-ability students."

Among the responses attributing socio-economic factors to poor achievement were: 
- "Support from the family - economic support for books, educational visits and general opportunities within family life are greatly reduced with less money."

- "Poverty can also mean that those students cannot afford to stay in education and must begin work as soon as possible. This could mean that they do not achieve their full academic potential."

- "Pupils coming from a poor background have less choices in their education and often no one is helping them realise that they can actually do it."

The next question (Table 4), explored the question of whether the student teachers believed that their views on poverty had changed during the course:

Over the course of the PGCE year, do you think that your views about the link between poverty and pupils' educational outcomes and life choices have changed : $n=166$

\begin{tabular}{|l|l|l|}
\hline & Number & $\%$ \\
\hline Completely Changed & 6 & $4 \%$ \\
\hline Changed a little & 94 & $57 \%$ \\
\hline No change & 66 & $40 \%$ \\
\hline
\end{tabular}

Table 4

On the face of it, the fact that only $4 \%$ had their views completely changed and only $61 \%$ reported any change at all might be surprising. Of course the data do not address the question of how their views have changed. It may be that those with entrenched or developed views only had these ideas confirmed by their experiences. However, the coding of the qualitative data from the open question that asked the students to give reasons for a change of view, suggests that both the university programme (66 comments) and the school placements (107 comments) had influenced the $61 \%$ whose views had changed (Tables 5 and 6).

Elements of the University-based programme as a shaping influence:

\begin{tabular}{|l|l|l|l|l|l|l|}
\hline & PDP & Peers & Assignments & Outside & Curriculum & Tutors \\
\hline
\end{tabular}




\begin{tabular}{|l|l|l|l|l|l|l|}
\hline & & & & experiences & sessions & \\
\hline Number & 53 & 2 & 2 & 1 & 6 & 2 \\
\hline$\%$ & 80 & 3 & 3 & 1.5 & 9 & 3 \\
\hline
\end{tabular}

Table 5

Aspects of the school placements as a shaping influence:

\begin{tabular}{|l|l|l|l|l|l|l|}
\hline & $\begin{array}{l}\text { Working } \\
\text { with } \\
\text { pupils }\end{array}$ & $\begin{array}{l}\text { Working } \\
\text { with } \\
\text { teachers }\end{array}$ & $\begin{array}{l}\text { Own } \\
\text { observations } \\
\text { and } \\
\text { reflections }\end{array}$ & Peers & $\begin{array}{l}\text { Communicating } \\
\text { with Parents }\end{array}$ & Other \\
\hline Number & 61 & 16 & 18 & 1 & 7 & 4 \\
\hline$\%$ & 57 & 15 & 17 & 1 & 6.5 & 3.5 \\
\hline
\end{tabular}

Table 6

From the university side of the course, the PDP session seems to have been quite important as an influencing factor. This is despite, or perhaps because of, the fact that the main focus on these issues was delivered at the very start of the course. However, it is also clear that working with pupils also helped to shape prospective teachers' views. In this way the theoretical provocations provided in the PDP session may have been an important catalyst for many student teachers' reflections on their subsequent school experience. Yet, as the focus group interview exemplified, we would argue that this aspect of experience was very dependent on the social composition of placement schools. It is also striking that very few student teachers had experienced interactions with parents that had influenced them. This contrasts sharply with the experience of a minority of the student teachers who described themselves as being placed in schools with significant levels of social deprivation:

"My [first placement] school had a high proportion of FSM pupils and vulnerable children which gave me the opportunity to deepen my understanding of these issues through working with the children in a pastoral setting and in the classroom. Furthermore, dealing with parents on the phone and face to face gave me a wider awareness of issues in the home and how this can influence children's attitudes to learning and responses to adults in a school environment." 
If direct experience of poverty is key then one might argue that Teach First, with its concentration on schools in disadvantaged areas, could be more effective at preparing teachers to meet the needs of children living in poverty, than a PGCE programme such as the Oxford one, located in a more affluent context - albeit with pockets of poverty. At the same time it is clear that the theoretical prompts and research readings from the University programme did challenge some student teachers' assumptions about poverty. These are issues that HEI/school partnerships need to consider carefully if all student teachers are to learn fully from both theory and implications for practice in a variety of school contexts.

Towards the end of the PGCE course, we conducted a small focus group of PGCE student teachers. All three female prospective teachers who participated (one each from English, Religious Education and Modern Foreign Languages subject groups) described themselves as coming from middle class families who had encouraged and supported them in their education. Only Student Teacher $\mathrm{C}$ had had a parent who had attended university. The three were currently placed on their second placement at a successful Oxford comprehensive school with relatively low levels of child poverty. However, the three had had very differing first placements in comprehensive schools: Student Teacher A was placed in a rural school; Student Teacher B was in a school in a medium sized affluent town; Student Teacher C was in an inner city school with significant levels of child poverty. Whilst all three felt that they had been challenged both by University tutors and their school mentors to think about issues of poverty, their responses to the question of whether there is a direct link between poverty and education differed:

"I'm a bit undecided. I think I'm sort of reluctant to accept the idea that poverty is necessarily linked to educational success. ... it's more the, not emotional poverty, but maybe also the intellectual poverty that I find is more of an issue than necessarily the monetary poverty." (Student Teacher A).

"I think that there's a link between wealth and education. Because if you're not from a wealthy background and you're thinking about your future, your future might be to support the rest of your family or to just kind of go into the same track as your family and you might not have the opportunities to look outside of that." (Student Teacher B). 
"I think there are definitely... from what I've seen there seems to be a link particularly from the school I was in seeing where they were headed, where their aspirations were. It was completely contrasted with the new placement where everyone wants to go to university, everyone wants to go and do jobs that require a degree." (Student Teacher C).

Student Teacher A believed that lack of "cultural capital" was the most important factor. However, she also contrasted the lack of aspiration shown by rural children from fairly affluent farming families with children from immigrant families who "really valued education."

"I think I had some cases ...where really the atmosphere at home was sort of more against school and probably based on a negative experience themselves that they had in school. But there were some children from immigrant backgrounds I could actually see that the parents really valued education and wanted their children to do well."

Student Teacher B saw a direct link between poverty and attainment and also felt that pupils from less privileged backgrounds were often ignored because of the school's and teachers' cultural expectations of the norm.

"The school kind of overlooked those students who were impoverished because they just looked at the big majority which were the wealthier students, and they just assumed that everybody was like that and they kind of didn't see necessarily what was in front of them."

Student Teacher $\mathrm{C}$ also talked about aspirations, but her experience in the inner city school left her both frustrated by bright pupils who did not seem to her to value education but also realistic about the material problems facing poorer pupils. She also viewed lack of parental support for the possibilities of education as the most important aspect link between poverty and low attainment:

"I think that's what really became apparent from the parents' evening that I came to, it was trying to convince the parents that education was good. First of all most of the parents you could see they had a negative experience of school themselves, so you could 
definitely see that being communicated to their children. And I think having that attitude falling down was just... I found it really difficult to try and change it because their immediate role models were giving them some really negative opinions about education."

All three felt that the course had to a large degree changed their perceptions of the effects of poverty on pupil well-being and attainment. They were all sensitive to the plight and needs of pupils from impoverished backgrounds. However, their experience in schools led them to believe that low aspirations and parental negative attitudes to school were all pervasive and the key indicator for poor performance in school.

\section{Discussion and Conclusions}

This research raises many important questions about the cohort's limited understanding of the link between child poverty and educational achievement. One of the key questions is the extent to which student teachers understand both the material and cultural effects of poverty and educational achievement and expectations. For if, as the majority appear to believe, good education makes a difference to social mobility, then what is the effect of student teachers who accept the idea of a 'culture of poverty' and accept deficit models of the pupils they aim to inspire? What are the implications for children who live in poverty if stereotypical views abound within the teaching profession about them, their families and their communities? How should ITE programmes intervene to ensure that such views are challenged? And does the experience of working in schools change previously entrenched views?

PGCE student teachers are influenced both by the theoretical and pedagogical sessions at their university and the practical experience and contexts of their placement schools. They work in partnership with both their university curriculum tutors and school mentors (Hayward,1997). The interactions and lessons learned from these layers of expertise is a dialectical and contradictory process. McIntyre (1993) defined this dialectical relationship as 'practical theorising' by which the student teachers aim to understand theory through evaluating practice. But student teachers' experiences and indeed their preconceptions will differ in their university settings and in the contexts of the schools. As we have seen, for some of our student teachers, opportunities to communicate directly with parents were particularly influential in developing understandings; but not all had had opportunities to 
communicate with families living in poverty. Some of our partnership schools are located in relatively affluent areas and the poverty that does exist will often be invisible in the classroom and in the wider school. Moreover, if as Gazeley and Dunne (2005) suggest, the 'culture of poverty' is pervasive in schools and amongst teachers, it is unlikely that our student teachers' perceptions will be challenged and in time altered. Given how much of the PGCE course is spent in school, deficit views could in fact be entrenched rather than challenged. And as 'lowly' student teachers, few will be able to challenge deficit views about poor pupils and their families. Unsurprisingly then, for a sizeable minority of our student teachers, little had changed; the reason why children living in poverty do less well at school compared to their more affluent peers was laid fairly and squarely at the door of the pupils themselves and their families.

This study and the data it generated is not without considerable limitations, not least in what can be claimed in more general terms. Another major limitation of our data is that they do not help us to understand in detail the process of change or analyse the complex interplay between the contexts of school and university. This of course will require more in-depth studies in multiple and diverse settings; thus, in the future, it is our aim to seek collaboration with other ITE providers within the PATE research group in order to widen the evidence base drawn from our own cohort of student teachers.

As a question of addressing social justice, we believe that it is imperative that university and school collaborators unite to challenge the social and cultural assumptions about the impacts of poverty held by many of our student teachers. However, we are able to make the tentative suggestion that teacher education programmes can challenge some entrenched views through: professional development programmes; the school environment; exposure to relevant theory; reading relevant research and policy literature. At the same time, our data sets suggest that deficit models are widely accepted by many student teachers who see 'aspirations' (negative or positive) as more important than social class or poverty. A lack of opportunity to develop better understandings about the lives of those who live in poverty will only perpetuate ignorance amongst student teachers; in Gorski's words, stereotyping will persist as student teachers 'fill in the blanks' about pupils, their families and their communities (Gorski 2012, p. 303). We know that a deficit view can lead to low expectations and that this in turn can impact negatively on the effectiveness of teaching. On the other hand, understanding the 
impact of material conditions on children's learning may be something that beginning teachers feel deeply frustrated about - after all they cannot by themselves reverse economic patterns of disadvantage and inequality. Nevertheless they can be supported in developing an ambitious and critical approach to their teaching based on a commitment to overcoming the impacts of poverty on young people's learning. Because, if we don't challenge the 'culture of poverty' and its impact on teachers' classroom practice, then our social justice agenda will achieve nothing (Zeichner 2009).

\section{References}

Ball, S. J. (2003) Class Strategies and the Education Market: The Middle Classes and Social Advantage. London and New York: RoutledgeFalmer.

Ball, S. J. (2006) Education policy and social class: The selected works of Stephen J Ball. London: Routledge.

Benton, P. (ed) (1990) The Oxford Internship Scheme. London: Calouste Gulbenkian Foundation.

Bernstein, B. (1970) Education cannot compensate for society. New Society, 15 (387): 34447.

Buras, K. L. (2014) There Really Is a Culture of Poverty: Notes on Black Working-Class Struggles for Equity and Education. In P. C. Gorski \& J. Landsman, (eds.). The Poverty and Education Reader: A Call for Equity in Many Voices. Stylus Publishing, LLC, pp. 60-75.

Clark, M. L. (1985). Social stereotypes and self-concept in Black and White college students. The Journal of Social Psychology, 125 (6): 753-760.

Cochran-Smith, M. (2004) Walking the Road-Race, diversity and social justice in teacher education. New York: Teachers' College Press. 
Cochran-Smith, M. \& Zeichner, K.M. (eds) (2010) Studying teacher education: The report of the AERA panel on research and teacher education. London and New York: Routledge.

Cox, B. J. , Watts, C. \& Horton, M. (2012) Poverty Perceptions of Pre-Service Teachers and Social Work Candidates. Journal of Studies in Education, 2(1):131-148.

Cummings, C. , Laing, K., Law, J., McLaughlin, J., Papps, Todd, L. \& Woolner, P. (2012) Can changing aspirations and attitudes impact on educational attainment? A review of interventions. York: Joseph Rowntree Foundation.

Darling-Hammond, L. \& Bransford, J. (eds.) (2007). Preparing teachers for a changing world: What teachers should learn and be able to do. New York: John Wiley \& Sons.

Department for Education (2010) The Importance of Teaching: The Schools White Paper 2010. London: DfE.

Department for Education (2013) Teachers' Standards Guidance for school leaders, school staff and governing bodies. London: DfE.

Dorling, D. (2011) Injustice - why social inequality persists. Bristol: The Policy Press.

Dudley-Marling, C., \& Lucas, K. (2009). Pathologizing the language and culture of poor children. Language Arts, 86(5): 362-370.

Freeman, L. (2007) An overview of dispositions in teacher education. In M.E. Diaz and J. Raths (eds.) Dispositions in Teacher Education. Charlotte, N.C.: Information Age Publishing.

Gazeley, L. \& Dunne, M. (2005), Addressing Working Class Underachievement. University of Sussex.

Gorman, E. H. (2005). Gender stereotypes, same-gender preferences, and organizational variation in the hiring of women: Evidence from law firms. American Sociological Review, 70(4): 702-728. 
Gorski, P. C. (2011) Unlearning deficit ideology and the scornful gaze: Thoughts on authenticating the class discourse in education." In R. Ahlquist, P. Gorski \& T. Montaño (eds) Assault on kids: How hyper-accountability, corporatization, deficit ideologies, and Ruby Payne are destroying our schools. New York, NY: Peter Lang.

Gorski, P. C. (2012) Perceiving the problem of poverty and schooling: Deconstructing the class stereotypes that mis-shape education practice and policy. Equity \& Excellence in Education, 45.2: 302-319.

Gorski, P. C. \& Landsman, J. (2013) (eds.) The Poverty and Education Reader: A Call for Equity in Many Voices. LLC: Stylus Publishing.

Hagger, H. and McIntyre, D. (2000). What can research tell us about teacher education? Oxford Review of Education, 26(3-4), 483-494.

Hayward, G. (1997) Principles for school focused initial teacher education: some lessons from the oxford Internship Scheme, in T. Allsop \& A. Benson (eds.) Mentoring for science teachers. Buckingham: Oxford University Press.

Hills, J., Brewer, M., Jenkins, S. P., Lister, R., Lupton, R., Machin, S., Mills, C., Modood, T., Rees, T. \& Riddell, S. (2010) An Anatomy of Economic Inequality in the UK: Report of the National Equality Panel. London: Centre for Analysis of Social Exclusion, London School of Economics and Political Science

Horgan, G. (2007) The impact of poverty on young children's experience of school. York: Joseph Rowntree Foundation.

Hurst, C. (2007). Social inequality: Forms, causes, and consequences. Boston, MA: Pearson.

Ladson-Billings, G. (2006) It's not the culture of poverty, it's the poverty of culture: the problem with teacher education. Anthropology and Education Quarterly, 37 (2): 104-109. 
Love, B. J. (2004). Brown plus 50 counter-storytelling: A critical race theory analysis of the “majoritarian achievement gap" story. Equity \& Excellence in Education, 37(3), 227-246

Lupton, R. (2006) How does place affect education?' In S. Delorenzi (ed.) Going Places: Neighbourhood, Ethnicity and Social Mobility. London: Institute of Public Policy Research.

Lupton, R. and Thrupp, M. (2013) Headteachers' Readings of and Responses to Disadvantaged Contexts: evidence from English primary schools. BERJ, 39(4): 769-788.

Marshall, G. (2002) Repositioning Class: Social Inequality in Industrial Societies. London: Sage.

McIntyre, D. (ed.) (1997) Teacher Education Research in a New Context. London: Paul Chapman.

Nieto, S. (2000) Placing Equity Front and Center: Some Thoughts on Transforming Teacher Education for a New Century. Journal of Teacher Education, 51 (3):180-187

Pajares, M. F. (1992) Teachers' beliefs and educational research: Cleaning up a messy construct. Review of Educational Research, 62(3), 307-332.

Patterson, J. A., Hale, D. \& Stessman, M. (2007). Cultural contradictions and school leaving: A case study of an urban high school. The High School Journal, 91(2):1-15.

Payne, R. (2005). A Framework for Understanding Poverty. Highland, TX: Aha! Process, Inc.

Raffo, C., Dyson, A., Gunter, H., Hall, D., Jones, L.\& Kalambouka, A. (2007) Education and Poverty: a critical review of theory, policy and practice. York: Joseph Rowntree Foundation. 
Rank, M. R., Yoon, H.-S. \& Hirschl, T. A. (2003). American poverty as a structural failing: Evidence and arguments. Journal of Sociology and Social Welfare, 30(4): 3-29.

Richardson, V. (1996). The role of attitudes and beliefs in learning to teach. In J. Sikula (ed.) Handbook of research on teacher education. New York: Macmillan.

Sleeter, C. E. (2004). Context-conscious portraits and context-blind policy. Anthropology \& Education Quarterly, 35(1): 132-136.

Somekh, B. \& Lewin, C. (eds.) (2011). Theory and methods in social research. Thousand Oaks, CA: Sage.

Teddlie, C. \& Tashakkori, A. (2009) Foundations of Mixed Methods Research : Integrating Quantitative and Qualitative Approaches in the Social and Behavioral Sciences. Thousand Oaks, CA: Sage.

Thrupp, M., Mansell, H., Hawksworth, L. \& Harold, B. (2003) 'Schools can make a difference'- but do teachers, heads and governors really agree? Oxford Review of Education, 29 (4): 471-484.

Valencia, R. R. (1997). Introduction. In R. R. Valencia (Ed.), The evolution of deficit thinking (pp. ix-xvii). London, England: Falmer.

Villegas, A. M. (2007) "Dispositions in teacher education a look at social justice." Journal of Teacher Education 58, 5 370-380.

Villegas, A. M., \& Lucas, T. (2002). Preparing culturally responsive teachers rethinking the curriculum. Journal of teacher education, 53(1), 20-32. 
Wideen, M., Mayer-Smith, J., \& Moon, B. (1998). A critical analysis of the research on learning to teach: Making the case for an ecological perspective on inquiry. Review of Educational Research, 68(2): 130-178.

Wilkinson, R. \& Pickett, K. (2010) The Spirit Level - why equality is better for everyone. London: Penguin.

Zeichner, K. (2009) Teacher Education and the Struggle for Social Justice. New York and London: Routledge. 